\title{
Bazı Vahşi Kuşlarda Trichinella spp. Larvasının Araştırılması
}

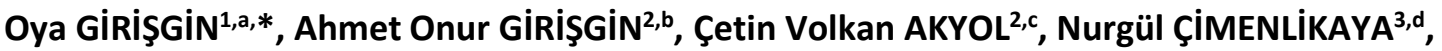 \\ Betül SAYGIN ${ }^{3, e}$
}

\author{
${ }^{1}$ Bursa Uludağ Üniversitesi, Karacabey Meslek Yüksekokulu, Karacabey, Bursa, Türkiye. \\ ${ }^{2}$ Bursa Uludağ Üniversitesi, Veteriner Fakültesi, Parazitoloji Anabilim Dalı, Nilüfer, Bursa Türkiye. \\ ${ }^{3}$ Bursa Uludağ Üniversitesi, Sağlık Bilimleri Enstitüsü, Nilüfer, Bursa, Türkiye. \\ aORCID: 0000-0001-9896-1093, bORCID: 0000-0002-0020-2708, CORCID: 0000-0001-6522-6746, \\ dORCID: 0000-0001-9727-0522, e ORCID: 0000-0002-3190-1261
}

\begin{abstract}
Özet: Zoonoz bir hastalık olan trişinelloz hastalığının etkeni Trichinella spp. larvaları, genelde memelilerde ve bazen kuşlarda bulunmaktadır. Etkenin Türkiye'deki dağııımı daha çok yaban domuzlarıyla olmakla birlikte, yaban hayatta diğer memelilerle de olabilmektedir. Larvalar kuşlarda da bulunabildiğinden dolayı, bu çalışma, kuzeybatı Türkiye'deki bazı yabani kuşlarda Trichinella spp. larvalarının varlığını tespit etmek amacıyla yapılmıştır. Bu amaçla, hayvan hastanesine tedavi amacıyla getirilen ve ölen 59 yabani kuşa nekropsi yapılarak, göğüs kaslarında larva varlığı, yapay sindirim tekniği ile araştırılmıştır. Örneklerdeki muhtemel pozitifliği teyit etmek amacıyla, aynı zamanda her örnek ayrıca Trişinoskop ile de muayene edilmiştir. Yapılan muayeneler sonucunda hiçbir kuşun göğüs kasında Trichinella spp. larvalarına rastlanmamıştır. Larva tespiti yapılmadığı için, tür teşhisine yönelik herhangi bir moleküler çalışma da yapılamamıştır. Çalışmamız, Türkiye'deki yabani kuşlarda Trichinella spp. larvalarının varlığının araştırılmasına yönelik ilk çalışmadır.
\end{abstract}

Anahtar Kelimeler: Bursa, Trichinella spp., Yabani kuşlar.

\section{Investigation of Trichinella spp. Larvae in Some Wild Birds}

\begin{abstract}
Trichinella spp. larvae of the zoonotic trichinellosis may occur mainly in mammals either birds. The distribution area of the agent is influenced by the introduction of this pathogen strongly by wild boars and other wild mammals in the wildlife of Turkey. Since larvae can also be found in birds, we surveyed to detect this parasite in wild birds in northwest Turkey via examining breast muscles from 59 wild birds by artificial digestion. Each sample was examined under the stereomicroscope after the digestion protocol. At the same time, every sample was examined separately by the Trichinoscope to support possible positivity. As a result of this investigation, none of the larvae were detected in sampled birds. Because of no larva detection, none of a specific molecular test was performed. This is the first documentation about the presence of Trichinella larvae in birds in Turkey.
\end{abstract}

Keywords: Bursa, Trichinella spp., Wild birds.

\section{Giriş}

Trişinelloz, Trichinella türlerinin larvalarını bulunduran etlerin veya et ürünlerinin çiğ veya az pişmiş olarak yenmesi sonucu oluşan, dünyadaki yaygın zoonoz hastalıklardan biridir. Bu cinse ait nematodlar, Antarktika hariç tüm dünyada memelilerin, kuşların ve sürüngenlerin parazitidir. Kırsal döngüde bulunan hayvanlardan kemirgenler, kara ve kutup ayıları, yaban domuzu, porsuk, kurt, tilki, büyük kediler, sırtlan, çakal gibi yırtıcılar başta olmak üzere, yabani kuşlar da hastalığın epidemiyolojisinde rol oynamaktadır. Enfeksiyon, taze veya çürümüş hayvan leşlerinde bulunan kist içindeki larvaların alınması veya bazı enfekte hayvanların dışkılarının yenmesi ile gelişmektedir. Hastalık insanlara, evcil veya yabani domuzlar, karnivorlar (örn; ayı, köpek, porsuk, mors) ve atlara ait et/et ürünlerinin çiğ veya az pişmiş olarak yenmesiyle bulaşmaktadır (Pozio, 2005; 2007;
2015). T. pseudospiralis türü, hem memeliler hem de kuşlarda bulunabilen tek türken, diğer Trichinella türleri memelilerde veya sürüngenlerde bulunmaktadır (Pozio, 2005). Türkiye'de domuz eti tüketimi dinsel nedenlerden dolayı çok azdır. Raporlanan insan trichinellosis vakalarının hepsinin yaban domuzu kökenli olması, vahşi yaşamdan avlanan yaban domuzlarının bir kısım halk tarafından yendiğini göstermektedir.

Türkiye'de özellikle domuz ve domuzdan elde edilen gıda ürünlerinde Trichinella larvalarının varlığına yönelik birçok araştırma yapılmasına rağmen (Aypak ve ark., 2013; Bostan ve ark., 1999; Heper ve ark., 2005; Şenlik ve ark., 2011), kırsal döngüde bulunan yabani kuşlardaki larva varlığına yönelik herhangi bir çalışma bulunmamaktadır. Bu çalışmada, Bursa il sınırları içerisinde bulunan, Bursa Uludağ Üniversitesi Hayvan Hastanesine tedavi 
amacıyla getirilen yabani kuşların göğüs kaslarında Trichinella spp. larvalarının varlığı araştırılmıştır.

\section{Materyal ve Metot}

Çalışma yapılmadan önce, kuşlar üzerinde yapılacak uygulamalar için Uludağ Üniversitesi Hayvan Deneyleri Yerel Etik Kurulundan (No:2015-
06/03) ve T.C. Orman ve Su İşleri Bakanlığı'ndan (29.06.2015, No: 138216) gerekli izinler alınmıştır.

Bursa Uludağ Üniversitesi Veteriner Fakültesi Hayvan Hastanesine Haziran 2015-Ocak 2019 tarihleri arasında halk tarafından yaralı olarak getirilen ve tedaviye rağmen ölen yabani kuşlar, bu çalışmanın materyalini oluşturmuştur. Toplamda 17 cinse ve 19 türe ait 59 adet yabani kuş, Trichinella spp. larvaları yönünden muayene edilmiştir (Tablo 1).

Tablo 1. Çalışmada incelenen kuş türleri ve sayıları

\begin{tabular}{|c|c|c|}
\hline Kuş ismi (Lat) & Kuş ismi (TR) & $\mathbf{n}$ \\
\hline Buteo buteo & Şahin & 12 \\
\hline Passer domesticus & Bayağı serçe & 9 \\
\hline Larus michahellis & Gümüş martı & 9 \\
\hline Ciconia ciconia & Leylek & 4 \\
\hline Pica pica & Saksağan & 4 \\
\hline Tyto alba & Peçeli baykuş & 3 \\
\hline Corvus monedula & Küçük karga & 3 \\
\hline Apus apus & Ebabil & 3 \\
\hline Falco tinnunculus & Kerkenez & 2 \\
\hline Falco eleonorae & Ada doğanı & 1 \\
\hline Circaetus gallicus & Yılan kartalı & 1 \\
\hline Apus melba & Ak karınlı ebabil & 1 \\
\hline Upupa epops & İbibik & 1 \\
\hline Corvus corone & Kara leş kargası & 1 \\
\hline Caprimulgus europaeus & Çoban aldatan & 1 \\
\hline Columba livia & Kaya güvercini & 1 \\
\hline Anthus trivialis & Ağaç incirkuşu & 1 \\
\hline Corvus cornix & Leş kargası & 1 \\
\hline Toplam & & 59 \\
\hline
\end{tabular}

Kuşların tür teşhisleri Heinzel'in (1995) tanımladığı kriterlere göre yapılmıştır. Kuşlar genel nekropsi kurallarına göre açılarak göğüs (pektoral) kaslarından, kuşun büyüklüğüne göre 2-4 gr'lık parçalar alınmıştır. Her bir kas örneği Trichinella larvalarının varlığı yönünden, manyetik karıştırıcılı yapay sindirim tekniğiyle incelenmiştir (European commission regulation 2075/2005; Gamble ve ark, 2000). Sindirim sıvılarındaki larvaların varlığı stereomikroskop (Nikon SMZ 10) altında $\times 35$ büyütmede muayene edilmiştir. Ayrıca ikinci bir muayene yöntemi olarak, her kuşun ortalama 1 gramlık göğüs etleri ince parçalar halinde kıyılarak Trişinoskop lamı arasında ezilmiş ve aynı mikroskop altında aynı büyütmede muayene edilmiştir (Kaya, 2003).

\section{Bulgular}

Bu çalışma süresince Bursa il sınırları içerisinde bulunarak hayvan hastanesine tedavi amacıyla getirilen ve ölen 59 yabani kuşun göğüs kasları Trichinella spp. larvalarının varlığı yönünden muayene edilmiştir. Gerek sindirim tekniğiyle gerekse trişinoskop lamında yapılan muayeneler sonucunda örneklerin hiçbirisinde Trichinella spp. larvalarına rastlanmamıştır. 


\section{Tartışma ve Sonuç}

Dünyada yaygın olarak görülen zoonoz hastalıklardan biri olan Trişinelloz; memeliler, kuşlar ve sürüngenlerde bulunan Trichinella türlerinin larvaları tarafından oluşturulur. Zoonoz karakterli hastalık olması, Trichinella spp. larvalarının hayvanlarda bulunma oranının araştırılması ve bilinmesi yönünden önem arz etmektedir.

Trichinella spiralis'in orijini Doğu Asya olup, muhtemelen ticaret yolu ile Avrupa'ya yayılmış, Avrupa kolonizasyonu sırasında ikinci milenyumun başlarında Amerika, Yeni Zelanda ve Havai'ye de yayılım gösterdiği belirtilmiştir (Pozio, 2019).

Türkiye'de ilk Trişinellozis vakası 1977 yılında Merdivenci (1977) tarafından bildirilmiştir. Kastamonu'da avlanan yaban domuzunun İstanbul'da bulunan bir aile tarafından satın alınması ve tüketilmesi sonucunda on üç kişinin enfekte olduğu tespit edilmiştir. 2003 yılında Bursa'da yabani domuz eti yemiş olan yedi kişinin klinik semptomlar göstermesi üzerine yapılan testlerle Trişinellozis varlığı tespit edilmiştir (Heper ve ark., 2005). Mart 2004'te İzmir'de çiğ köfte tüketim öyküsü bulunan 474 kişiden 154'üne Trişinellozis tanısı konmuştur (Türk ve ark., 2006). İki bin beş yılında İzmir'de Trişinellozdan şüphelenilen 76 çocuğun 47'sinin seropozitif olduğu belirlenmiştir (Ozdemir ve ark., 2005). Şubat 1997 'de İstanbul'da Bulgaristan'dan getirilen yabani domuz etinden yapıldığı belirlenen sosislerde Trichinella spp. larvalarına rastlanmıştır (Bostan ve ark., 1998).

Türkiye'de hayvanlarda Trichinella spp. prevalansı ile ilgili yapılan çalışmalar yetersizdir. İlk olarak Rommel (1971) tarafından Ankara Polatlı'da 70 yaban domuzunda yapılan çalışmada, domuzların sadece bir tanesinde Trichinella spp. enfeksiyonu tespit edilmiştir. 1979-1983 yılları arasında 535 evcil domuz, 1165 yaban domuzu ve 600 domuz ürünü incelenmiş ve sadece 1165 yaban domuzunun ikisinde Trichinella spiralis bulunmuştur (Nazlı, 1985). 2007-2008 yılları arasında Bursa'da 27 yaban domuzu üzerinde yapılan çalışmada Trichinella spp. larvaları saptanmamıştır (Senlik ve ark., 2011). Aypak ve arkadaşları (2013), 2007-2009 tarihleri arasında Aydın illinde avlanan 43 yaban domuzunda Trichinella spp. varlığını araştırmış ve domuzların hiçbirisinde Trichinella spp. larvalarına rastlamamıştır. Türkiye'de yaban hayatındaki kurtlarda yapılan çalışmada ilk defa Trichinella britovi tespit edilmiştir (Erol ve ark., 2020).

T. pseudospiralis, hem memelileri hem de kuşları enfekte etmektedir (Pozio ve Murrell, 2006). Insanda 2000 yılında Fransa'da, 2015'te İtalya'da tespit edilmiştir (Gómez-Morales ve ark., 2021; Ranque ve ark., 2000). Avrupa'da yapılan çeşitli çalışmalardan elde edilen 90 adet $T$. pseudospiralis izolatının \%61'inin evcil ve yabani domuzlardan \%39'unun ise karnivorlardan izole edildiği bildirilmiştir (Pozio, 2019). Kuşlarda $T$. pseudospiralis'in oluşturduğu ilk doğal enfeksiyon 1980 yılında Shaikenov (1980) tarafından bildirilmiştir. Lindsay ve ark. (1995) Alabama'da bir siyah akbabanın göğüs ve trakeal kaslarında $T$. pseudospiralis larvalarını tespit etmiştir. Pozio (1999), Italya'da alaca baykuş ve küçük baykuşun göğüs kaslarında, Hurnikova ve arkadaşları (2014) ise İsveç'te alaca baykuşun pektoral kaslarında $T$. pseudospiralis larvalarına rastlamıştır. İtalya'da 2012-2013 yılları arasında 678 saksağan ve 120 leş kargasında yapılan çalışmada $T$. pseudospiralis larvası araştırılmış ancak hiçbir kuşta varlığı tespit edilememiştir (Mancianti ve ark., 2020). Çalışmamızda larva tespiti yapılamadığından dolayı, tür teşhisine yönelik moleküler teşhis yöntemi uygulanamamıştır.

Çalışmamız, Türkiye'deki yabani kuşlarda Trichinella spp. larvalarının varlığının araştırılması yönünden yapılan ilk çalışmadır. Etkenin zoonoz özelliği dikkate alındığında, Türkiye'deki varlığına yönelik farklı bölgelerde yeni araştırmalar yapılmalıdır.

\section{Kaynaklar}

Aypak S, Aysul N, Bakırcı S, Karagenç T, 2013: Aydın ilinde avlanan yaban domuzlarında Trichinella sp. varlığının araştırılması. Animal Health Prod and Hyg, 2 (2), $203-205$.

Bostan K, Akkaya H, Vuruşaner C, Aksu H, 1999: Fermente bir sucukta Trichinella spiralis olgusu. Türk Parazitol Derg, 23, 194-198.

Erol U, Danyer E, Sarimehmetoğlu HO, Utuk AE, 2021: First parasitological data on a wild grey wolf in Turkey with morphological and molecular confirmation of the parasites. Acta Parasit, 66, 687692.

European Commission Regulation (EC) 2075/2005, 2005: Laying down specific rules on official controls for Trichinella in meat. Official Journal of the European Union, 338, 60-82.

Gamble HR, Bessonov AS, Cuperlovic K, Gajadhar AA, van Knapen F, Noeckler K, Schenone H, Zhu X, 2000: International Commission on Trichinellosis: Recommendations on methods for the control of Trichinella in domestic and wild animals intended for human consumption. Vet Parasitol, 93 (3-4), 393-408.

Gómez-Morales MA, Mazzarello G, Bondi E, Arenare L, Bisso MC, Ludovisi A, Amati M, Viscoli C, Castagnola E, Orefice G, Magnè F, Pezzotti $P$, Pozio E, 2021: Zoonoses Public HIth, 68, 29-37.

Heinzel H, Fitter R, Parslow J, 1995: Pocket Guide to Birds of Britain \& Europe with North Africa \& the Middle East. Harper Collins Publishers Ltd, UK. 
Heper Y, Yilmaztepe F, Komitova R, Akalin H, Vutova K, Helvaci S, 2005: A trichinosis outbreak caused by wild boar meat in Turkey. Parasite, 12, 191-192.

Hurnikova Z, Hrckova G, Agren E, Komorova P, Forsman J, Chovancova B, Molnar L, Letkova V, 2014: First finding of Trichinella pseudospiralis in two tawny owls (Strix aluco) from Sweden. Helminthologia, 51 (3), 190-197.

Kaya G, 2003: Parazitoloji Temel ilkeler ve Laboratuvar Teknikleri. M. Kemal Üniversitesi Yayınları No:16, MKÜ Basımevi, Hatay, 146.

Lindsay DS, Zarlenga DS, Gamblet HR, Al-Yaman F, Smith PC, Blagburn BL, 1995: Isolation and characterization of Trichinella pseudospiralis garkavi, 1972 from a black vulture (Coragyps atratus). J. Parasitol., 81 (6), 920-923.

Mancianti F, Terracciano G, Sorichetti C, Vecchio G, Scarselli D, Perrucci S, 2020: Epidemiologic survey on Toxoplasma gondii and Trichinella pseudospiralis infection in corvids from Central Italy. Pathogens, 9, 336.

Merdivenci A, Aleksanyan V, Girişken G, Perk M, 1977: Türkiye'de insanda ve yabani domuzda Trichinella spiralis enfeksiyonu olgusu. İstanbul Üniv Vet Fak Derg, 3, 46-71.

Nazlı B, 1983: Türkiye'de evcil ve yabani domuzlar ile bunlardan hazırlanan et preparatlarında Trichinella spiralis'in mevcudiyeti üzerine araştırmalar. Doktora tezi, ï̈ Sağlık Bilimleri Enstitüsü, İstanbul.

Ozdemir D, Ozkan H, Akkoç N, Onen F, Gurler O, Sari I, Akar S, Birlik M, Kargi A, Ozer E, Pozio E, 2005: Acute trichinellosis in children compared with adults. Pediatr Infect Dis J, 24, 897-900.

Pozio E, Goffredo M, Fico R, La Rosa G, 1999: Trichinella pseudospiralis in sedentary night-birds of prey from Central Italy. J Parasitol, 85 (4), 759-761.
Pozio E, Zarlenga DS, 2005: Recent advances on the taxonomy, systematics and epidemiology of Trichinella. Int J Parasitol, 35 (11-12), 1191-1204.

Pozio E, Murrell KD, 2006: Systematics and epidemiology of Trichinella. Adv in Parasit, 63, 367-439.

Pozio E, 2007: World distribution of Trichinella spp. Infections in animals and humans. Vet Parasitol, 149, 3-21.

Pozio E, 2015: Trichinella spp. İmported with live animals and meat. Vet Parasitol, 213, 46-55.

Pozio E, 2019: Trichinella and Trichinellosis in Europe. Vet Glasnik,73 (2), 65-84.

Ranque $S$, Faugère $B$, Pozio $E$, La Rosa G, Tamburrini $A$, Pellissier JF, Brouqui P, 2000: Trichinella pseudospiralis outbreak in France. Emerg Infect Dis, 6, 543-547.

Rommel M, 1971: Trichinose beim schwarzwild in der provinz Ankara. Ankara Üniv Vet Fak Derg, 18, 219221.

Shaikenov B, 1980: Spontaneous infection of birds with Trichinella pseudospiralis garkavi, 1972. Folia Parasitol (Praha), 27, 227-230.

Senlik B, Cirak VY, Girisgin O, Akyol CV, 2011: Helminth infections of wild boars (Sus scrofa) in the Bursa province of Turkey. J Helminthol, 85, 404-8.

Türk $M$, Kaptan F, Türker N, Korkmaz $M$, El S, Özkaya $D$, Ural S, Vardar I, Alkan MZ, Coskun NA, Turker M, Pozio E, 2006: Clinical and laboratory aspects of a trichinellosis outbreak in Izmir, Turkey. Parasite, 13, 65-70.

${ }^{*}$ Yazışma Adresi: Oya GiRişGiN

Bursa Uludağ Üniversitesi, Karacabey Meslek Yüksekokulu, Karacabey, Bursa, Türkiye.

e-mail: oyagirisgin@uludag.edu.tr 